\title{
Emergency Obstetric Kits: Knowledge, Attitudes and Practices of Health Care Providers
}

\section{Nguefack Félicitée ${ }^{1 *}$, Dongmo Roger ${ }^{2}$, Djoumessap Djoyou Christine Marquise ${ }^{3}$, Ourtchingh Clovis ${ }^{4}$, Neh Flora ${ }^{5}$, Dongmo sylvestre ${ }^{6}$, Nana Njotang Philip ${ }^{1}$, Ntsama Junie Annick ${ }^{1}$ and Tatah Sandra ${ }^{1}$}

${ }^{1}$ Faculty of Medicine and Biomedical Sciences, Yaoundé-University I, Cameroon

${ }^{2}$ District Hospital of Efoulan Yaounde, Cameroon

${ }^{3}$ Higher Institute of Medical Technology, Cameroon

${ }^{4}$ Regional Hospital of Maroua, Cameroon

${ }^{5}$ Ministry of Public Health, Family Health Division, Cameroon

${ }^{6}$ District Health Service of Mbengwi, Cameroon

*Corresponding author: Nguefack Félicitée, Faculty of Medicine and Biomedical Sciences, University of Yaounde I, P.O. Box 1364, Cameroon, Tel: +00-237-699-59-14-08, E-mail: dongfel@yahoo.fr

\begin{abstract}
Introduction: Emergency obstetric kits (EOK) improve the survival of mothers and newborns.

Method: A survey was carried out among 70 health care providers from health care facilities of the Maroua health district who use the EOK. We evaluated the knowledge on the components of the kits, the attitude of the personnel in case one of the components of the EOK is absent.

Results: More than half $(58.6 \%)$ of the staff interviewed were nursing assistants. The EOK for deliveries do not contain nonsterile examination gloves, while those for cesarean sections do not have analgesics. However, most staff $(72.8 \%)$ declared the delivery kit was complete; just as $74.1 \%$ declared the cesarean sections kit was complete. Only $10.0 \%$ of the staff knew that the foaming antiseptic solution was useful for simple deliveries, while $25.8 \%$ believed that Polyvidone iodine was unnecessary in the delivery kit. A minority of the staff knew that when one of the kit's components was unavailable, the hospital pharmacist was mandated to provide them and later renew the stock at the supply center. These were $31.4 \%$ and $33.3 \%$ of the respondents surveyed on delivery and cesareansection kits respectively. Most $(52.8 \%)$ gave a prescription to the family to purchase the missing component and $48.5 \%$ did not take any steps when it came to the cesarean kit.
\end{abstract}

Conclusion: A capacity building training on the usefulness and management of the kits would enable their optimal use in the fight against maternal and neonatal mortality.

\section{Keywords}

Knowledge, Attitudes, Practices, Obstetric kits, Composition, Supply

\section{Introduction}

Approximately 239 maternal deaths per 100,000 live births were registered in 2015 in 183 countries of the world [1]. Nearly all (99\%) occurred in developing countries [1] where the risk of death is 20 times higher than in developed countries [2]. Cameroon is one of the 15 sub-Saharan countries where Maternal Mortality Rates (MMR) are at unacceptably high levels [3]. According to the various health surveys carried out in this country, the MMR is increasing: from 430 to 782 deaths per 100,000 live births from 1998 to 2014 [4-6]; it was estimated in 2015 between 440 and 881 [2]. Several key factors contribute, among which a high level of poverty $[7,8]$. The northern area where the Maroua health district is located records the largest number of maternal deaths in Cameroon. A study conducted in 2007 showed that 1266 maternal deaths per 100,000 live births occur there [9]. These findings prompted the Government of Cameroon to take a commitment to achieve the sustainable development goal. To this effect, he would no 
longer be part of the countries with high maternal mortality beyond twice the world average [1]. One of its priorities was the introduction of Emergency Obstetric Kits (EOK). Knowledge of standards would be a prerequisite for implementing the strategy. The EOKs are made up of drugs and consumable medical supplies used to manage emergencies such as cesarean sections, incomplete abortions and ectopic pregnancies. The emergency bag on the other hand contains a stock of drugs and consumables medical supplies provided to health facilities for deliveries and Cesarean sections with complications. It would also serve to replace any deteriorated or missing components in the emergency kits. The Ministry of Health's recommendations state that in the event of a drug stock-out, the item should be taken from the emergency bag and served to the patient's family then later replaced by the Regional Medicine Provision Center (CAPR) and the Cameroon National Essential Drugs Procurement Center (CENAME). In this case, a material and consumable voucher at the equivalent price of the kit is issued for the family to obtain it. Since 2006 the EOK have been used in the northern part of Cameroon, initially with the support of the Project of Solidarity Approach to Reproductive Health (PASSAGE) project. The objective was to reduce financial barriers to quality childbirth by minimizing or canceling the third delay in care, an important and indirect cause of maternal and neonatal deaths, especially among the most disadvantaged $[10,11]$. However, abuses were observed at the time of their introduction. Insufficient knowledge of the composition and management of these EOKs could hamper the optimal use of this valuable aid. It was important to describe how much the staff knows about the EOKs; their attitudes and practices regarding it use during the process of delivery.

\section{Methodology}

The cross-sectional study was carried out from 1 March to 31 May 2015 in 10 maternity units of health facilities within the three health districts of Maroua, capital of the Far North Region. These were the Regional Hospital $(\mathrm{RH})$, the Sub-divisional Medicalized Health Center (CMA) and 7 public Integrated Health Centers (IHC).

We conducted an interview with the 70 staff concerning the management of Emergency Obstetric Kits (EOKs).
These personnel carried out deliveries either in maternity wards or in the operating room. A total of 27 staff were interviewed at the $\mathrm{RH}, 8$ in the CMA and 35 in the IHCs. We described their knowledge, attitudes, practices with respect to the EOK and the emergency bag by referring to the standards set by the Ministry of Public Health. The local composition of delivery and cesarean delivery kits was compared the contents listed in the national reference list. Staff needed to recognize useful but missing drugs and consumables, inadequate and unnecessary medications in these kits, as well as in the emergency bag. With respect to the Cesarean section kit, we interviewed only the $\mathrm{RH}$ health care providers. In order to describe the attitude and the practices of the personnel, we evaluated their behavior towards situations of stock-out of a component of the kits or of the emergency bag. The knowledge was good when the staff offered at least 2 correct answers; same was considered for the right attitude. However, the attitude of the staff was bad, when he/she did not take any action to deal with the problem observed. We also compared the EOKs in pharmacies with the national standard.

\section{Statistical Analysis}

Quantitative data were analyzed using SPSS software 18.0.0 and Excel 2007. We presented the continuous variables as proportions. The comparison between the variables was done using the Chi-square test. The odds ratio was used to investigate the influence of certain variables on the knowledge, attitudes and practices of healthcare providers, considering the significance threshold for $P<0.05$.

\section{Ethical Considerations}

Ethical clearance was granted for our study by the National Ethics Committee of the University of Douala. The informed consent of healthcare providers was obtained without financial compensation.

\section{Results}

\section{Qualification of staff}

Nursing Assistants (NA) were the most numerous, 41 (58.8\%); (Table 1).

\section{Local composition of obstetric kits in maroua}

Table 1: Qualifications of the interviewed health care providers.

\begin{tabular}{|l|l|l|}
\hline Characteristics & Number & Percentage \\
\hline Medical doctor & 02 & 2.8 \\
\hline Reproductive health nurse & 01 & 1.2 \\
\hline State registered nurse/State registered nurse anesthetist & 12 & 17.1 \\
\hline Midwife/Licensed practical nurse/Assistant nurse & 14 & 20.0 \\
\hline Nursing assistant & 41 & 58.6 \\
\hline Unspecified & 01 & 1.4 \\
\hline Additional training received & 31 \\
\hline Emergency obstetrical and neonatal care & 09 \\
\hline Prevention of mother to child transmission of HIV & 30 \\
\hline
\end{tabular}


The constitution of the local cesarean kit was almost in line with the official list, only two bottles of Perfalgan ${ }^{\circledR}$ were missing out of the 3 required. The delivery kit consisted of fewer gloves, i.e. 4 on the 8 required (Table 2).

\section{Knowledge of service providers on EOK}

The majority of staff (66.9\%) had no formal training on the use of EOKs. Almost 2/3 (74.3\%) said the delivery kit was complete. Some also cited antibiotics and paracetamol as missing items whereas these were actually part of the emergency bag. Only $10.0 \%$ reported the absence of foaming antiseptic for single deliveries. Eighteen healthcare providers (25.7\%) thought that Betadine

Table 2: Composition of the local kits at the Maroua regional hospital.

\begin{tabular}{|c|c|c|c|}
\hline Items & $\begin{array}{l}\text { Number in cesarean } \\
\text { section Kit }\end{array}$ & $\begin{array}{l}\text { Number in normal } \\
\text { delivery Kit }\end{array}$ & $\begin{array}{l}\text { Comparison with national } \\
\text { recommendations }\end{array}$ \\
\hline Sterile gloves, size $n^{\circ} 7.5$ & 2 pairs & 2 pairs & Right \\
\hline Sterile gloves, size $n^{\circ} 8$ & 2 pairs & - & Right \\
\hline Examination gloves size 7-8 & 4 pairs & 4 pairs & 8 for delivery kit \\
\hline Sterile gauze, $40 \times 40$ & 20 & 5 & Right \\
\hline Barr clamp & 1 & 1 & Right \\
\hline Umbilical clamp & _ & 1 & Right \\
\hline Polyvidone iodine $10 \%(200 \mathrm{ml})$ & 1 vial & 1 & Right \\
\hline Oxytocin $10 \mathrm{IU} / \mathrm{ml}$, (8 extra kit) & 3 ampules & 1 (extra kit) & Right \\
\hline Phyto metadione 10 mg/ml, & 1 ampule & 1 & Right \\
\hline Gentamycin eye drop $10 \mathrm{mg} / \mathrm{ml}$ & & 1 & Right \\
\hline Syringes, $10 \mathrm{ml}$, unit & 7 & 2 & Right \\
\hline Scalpel blade $n^{\circ} 23$ & 1 & - & Right \\
\hline Vicryl suture $n^{\circ} 2 / 0 \mathrm{CT}$ & 1 & - & Right \\
\hline Vicryl n¹/0 CT & 3 & - & Right \\
\hline Nylon suture $2 / 0$ & 1 & - & Right \\
\hline Plaster 18 x $5 \mathrm{~cm}, 50 \mathrm{~cm}$ & 1 & - & Right \\
\hline Ringer lactate $\mathbf{5 0 0 ~ m l ~}$ & 5 & - & Right \\
\hline Sodium chloride $0.9 \% 500 \mathrm{ml}$ & 3 & - & Right \\
\hline Infusor & 2 & - & Right \\
\hline Catheter $\mathbf{G 1 8}$ or $\mathbf{G 2 0}$ & 2 & - & Right \\
\hline Ampicillin $1 \mathrm{~g}$ injectable & 2 vials & - & Right \\
\hline Perfalgan $®$ & 1 vial & - & 3 for cesarean kit \\
\hline Urinary catheter CH 16 or 18 & 1 & - & Right \\
\hline Urine bag & 1 & - & Right \\
\hline Ketamine $\mathbf{5 0 0}$ & 1 ampule & - & Right \\
\hline Atropine injectable & 2 ampules & - & Right \\
\hline Diazepam injectable & 2 ampules & - & Right \\
\hline Paracetamol $500 \mathrm{mg}$ & 20 tablets & - & Right \\
\hline Diclofenac 75 mg/3 ml & 1 ampule & - & Right \\
\hline Glucose $5 \% 500 \mathrm{ml}$ & 2 & - & Right \\
\hline
\end{tabular}

Table 3: Knowledge of health care providers on components of the kits and management of the emergency bag.

\begin{tabular}{|c|c|c|c|}
\hline Question & Suggestion & Number (\%) & $\begin{array}{l}\text { Evaluation of } \\
\text { their answers }\end{array}$ \\
\hline \multicolumn{4}{|c|}{ Evaluation of the components of the delivery kit $(n=70)$} \\
\hline \multirow{4}{*}{$\begin{array}{l}\text { What useful drugs/consumables are missing in } \\
\text { the delivery kit? }\end{array}$} & Antibiotic & $9(12.9)$ & False \\
\hline & Paracetamol tablets & $3(4.3)$ & False \\
\hline & Antiseptic foaming solution & $7(10.0)$ & False \\
\hline & Nothing is missing & $51(72.8)$ & False \\
\hline \multirow{2}{*}{$\begin{array}{l}\text { Which components of the delivery kit are } \\
\text { useless? }\end{array}$} & Betadine (Polyvidone iodine) & $18(25.7)$ & False \\
\hline & None is useless & $52(74.3)$ & False \\
\hline \multicolumn{4}{|c|}{ Evaluation of the components of the cesarean kit $(n=27)$} \\
\hline \multirow[t]{4}{*}{ Which drugs are insufficient in the cesarean kit? } & Oxytocin & $2(7.4)$ & False \\
\hline & Sutures & $1(3.7)$ & False \\
\hline & Sterile gloves & $4(14.8)$ & False \\
\hline & Whole kit & $20(74.1)$ & False \\
\hline \multirow{3}{*}{$\begin{array}{l}\text { Who is responsible for the verification of the } \\
\text { contents of the emergency bag? }(N=51)\end{array}$} & Ward charge & $34(66.7)$ & False \\
\hline & Chief of the health facility & $15(29.4)$ & False \\
\hline & Delegation of public health & $2(3.9)$ & False \\
\hline
\end{tabular}


had no place in this kit (Table 3).

As for the cesarean section kit, all found its content useful and almost $3 / 4$ (74.1\%) said it was complete. Some reported that sterile gloves (14.8\%), utero-tonics (7.4\%) and sutures $(3.7 \%)$ were missing. Overall, $76.0 \%$ of staff had approximate knowledge on EOK. More than half $(52.2 \%)$ did not know that the cesarean section kit was also used for ectopic pregnancy operations.

\section{Attitudes and practices of personnel when drug stock-outs in the EOKs were encountered}

Almost half $(46.2 \%)$ of staff reported frequent drug stock-outs; however, only $31.4 \%$ eased provision of these drugs at the price designated for the kit by delivering a voucher to the patient or her family. The same was true for the cesarean kit (33.3\%). They (52.8\%) gave a prescription as usual and $48.1 \%$ did not do anything (Table 4). Some referred women to another maternity (18.4\%). For the drugs of the emergency bag, no respondent acted according to the standard procedure. Only $2.8 \%$ knew that the products were obtained from CAPR; $61 \%$ had good attitudes towards EOKs stock-outs.

State Registered Nurses (SRN) were more likely to display poor attitudes and practices $(O R=4, p=0.04)$. The qualification of the staff did not influence their knowledge, which did not influence their attitudes and practices either (Table 5).

\section{Discussion}

\section{Study limitation}

The purpose of the study was to ascertain whether the EOK users mastered their management and implementation. It covered only a minority of health care providers in public health facilities implementing the EOK; the private sector was not involved. Nursing Assistant (NAs) were more numerous and their level of education and basic training influenced the quality of the responses. In addition, the study was limited to a single health district and would not be representative of all personnel

Table 4: Attitude of health care providers towards delivery kits stock-outs.

\begin{tabular}{|c|c|c|c|}
\hline & & Number (\%) & $\begin{array}{l}\text { Evaluation of their } \\
\text { attitude }\end{array}$ \\
\hline $\begin{array}{l}\text { What do you do in case of delivery } \\
\text { kit stock-out? }\end{array}$ & $\begin{array}{l}\text { Give a prescription to the family for purchase } \\
\text { of the drugs and consumables }\end{array}$ & $37(52.9)$ & Inadequate \\
\hline \multirow{3}{*}{$(n=70)$} & Prepare an voucher for acquisition of the kit & $22(31.4)$ & Right \\
\hline & Refer the parturient to another health center & $7(10.0)$ & Inadequate \\
\hline & No action & $4(5.7)$ & Inadequate \\
\hline $\begin{array}{l}\text { What do you do in case of } \\
\text { cesarean section kit stock-out? }\end{array}$ & $\begin{array}{l}\text { The patient is expected to buy all the drugs } \\
\text { and consumables }\end{array}$ & $5(18.5)$ & Inadequate \\
\hline \multirow{3}{*}{$(n=27)$} & Prepare an voucher for acquisition of the kit & $9(33.3)$ & Right \\
\hline & Refer the parturient to another health center & $0(0.0)$ & Inadequate \\
\hline & No action & $13(48.1)$ & Inadequate \\
\hline \multirow{4}{*}{$\begin{array}{l}\text { Who is responsible for the } \\
\text { verification of the components of } \\
\text { the emergency bag }(n=70)\end{array}$} & Ward charge & $34(48.6)$ & Inadequate \\
\hline & Chief of the health facility & $15(21.4)$ & Inadequate \\
\hline & Regional delegation (CAPR) & $2(2.9)$ & Right \\
\hline & No response & $19(27.1)$ & Inadequate \\
\hline
\end{tabular}

Table 5: Knowledge, attitudes and practices of health care providers with regards to EOK according to their qualifications.

\begin{tabular}{|c|c|c|c|c|c|c|}
\hline & & \multicolumn{2}{|l|}{ Knowledge } & \multirow{2}{*}{ Total } & \multirow{2}{*}{ OR (IC) } & \multirow{2}{*}{$\mathbf{P}$} \\
\hline & & Poor N (\%) & Good N (\%) & & & \\
\hline \multirow{5}{*}{ 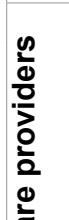 } & Medical doctor (M.D.) & $2(100)$ & $0(0.0)$ & 2 & $1.7(0.1-37.8)$ & 0.72 \\
\hline & Reproductive health nurse (RHN) & $1(100)$ & $0(0.0)$ & 1 & $1(0.6-26.1)$ & 1.06 \\
\hline & State registered nurse (SRN) & $7(58.3)$ & $5(41.7)$ & 12 & $0.3(0.1-1.3)$ & 0.18 \\
\hline & Licensed practicing nurse (LPN) & $10(76.9)$ & $3(23.1)$ & 13 & $1.1(0.2-4.6)$ & 0.91 \\
\hline & Nursing assistant (NA) & $32(78)$ & $9(22)$ & 41 & $1.4(0.4-4.2)$ & 0.53 \\
\hline $\bar{\mho}$ & Total & $52(75.4)$ & $17(24.6)$ & 69 & $5.5(7.2-74.1)$ & 0.51 \\
\hline 三 & & \multicolumn{2}{|c|}{ Attitudes and practices } & & & \\
\hline$\underset{\mathbb{J}}{\mathscr{0}}$ & & Poor N (\%) & Good N (\%) & & & \\
\hline \multirow{6}{*}{ 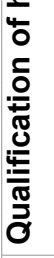 } & M.D. & $1(50.0)$ & $1(50.0)$ & 2 & $0.7(0.3-9.1)$ & 0.80 \\
\hline & RHN & $0(0.0)$ & $1(100)$ & 1 & $0.5(0.5-12.8)$ & 0.72 \\
\hline & SRN & $8(66.7)$ & 4 (33.3) & 12 & $4(1.1-14.9)$ & 0.04 \\
\hline & LPN & $2(15.4)$ & $11(84.6)$ & 13 & $0.2(0.8-1.1)$ & 0.06 \\
\hline & NA & $16(39)$ & $25(61)$ & 41 & $0.9(0.3-2.6)$ & 0.91 \\
\hline & Total & $27(39.1)$ & $42(60.9)$ & 69 & $6.3(1.3-0.5)$ & 0.11 \\
\hline \multirow{3}{*}{ 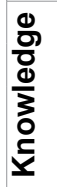 } & Poor & $23(43.4 \%)$ & $30(56.6 \%)$ & 53 & & \\
\hline & Good & $4(23.5 \%)$ & $13(76.5 \%)$ & 17 & $2.4(0.7-8.6)$ & 0.15 \\
\hline & Total & $27(38.6 \%)$ & $43(61.4 \%)$ & 70 & & \\
\hline
\end{tabular}


involved in the implementation of the EOK in the Far North Region.

In most developing countries, the factors identified as underlying causes of maternal and neonatal mortality are: family poverty, ignorance, the socio-occupational status of women, lack of social security, and weakness of health services [1]. Cameroon, like most countries in sub-Saharan Africa, has not at all achieved the goals of reducing maternal deaths [2], and the situation is particularly acute in the area where this study was conducted. Indeed, $54.8 \%$ of the Far North population is in the poorest economic welfare quintile [6]. Nearly $29.7 \%$ of women do not have access to paid work. In addition, maternal health indicators are of great concern in this part of Cameroon: high total fertility rate [8]; Low use of prenatal services (40\%); Low rate of modern contraception (3.0\%); Delivery rate by trained staff (59\%) with only $23.0 \%$ assisted by a nurse/midwife/nursing assistant and $2 \%$ by a physician; Cesarean section rate (0.5\%). A significant proportion of adolescents (34.4\%) begin their reproductive lives early and most child births (76\%) occur at home [6]. Figure 1 shows a model of causal analysis of factors that may limit access to services and obstetric care.

In areas where maternal and neonatal health indicators are poorly performing, strategies are being devel- oped to increase the use of obstetric services and improve the quality of emergency care [12]. It was in this context that each government was asked to mobilize all necessary resources to reduce deaths related to the third delay $[13,14]$. One of the main areas of intervention is to reduce the large catastrophic expenses incurred by families during childbirth [14]. In many countries, free care has been a means to reduce mortality by addressing financial barriers to access to quality childbirth [12,15-18]. In Cameroon, after the intervention of the PASSAGE project, the strategy of pre-positioning of kits had been effective since 2011. Its intention was to cover at least $70 \%$ of deliveries in health facilities in rural areas and $80 \%$ in urban areas as well as to increase the rate of cesarean sections. As described elsewhere [16], drug and consumables stock-outs are frequent in our context. Apart from acting on the third delay, the EOK system would also serve to reduce the lengthy procedures which consume enormous amounts of time between the decision to perform the cesarean section and its implementation [19]. Knowledge of standards would be a prerequisite for implementing the strategy. In the study area, the implementation of the EOK requires that the treating physician obtain the agreement of the hierarchy so that the pharmacy clerk can be used on credit for the cesarean section. However, not all health care

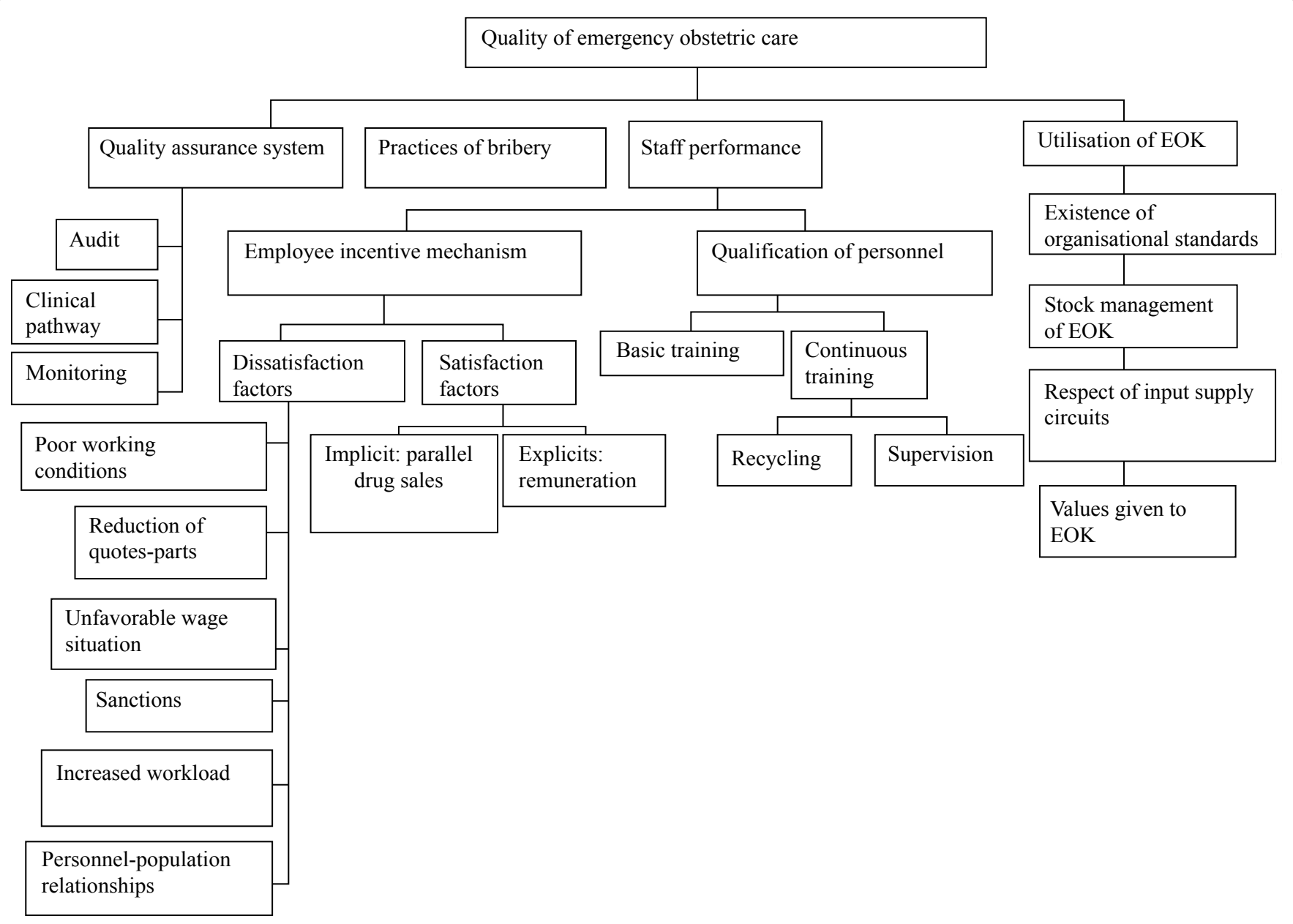

Figure 1: Model of analysis of the effect of financial barriers on access to care and solution provided by the implementation of the EOK policy. 
providers master the recommendations for use of the kits at the sites of our study. They did not get prior training in the use of EOK. Consequently, their attitudes varied according to the problem encountered; For example when it was necessary to complete a kit. In Burkina Faso, this situation has hampered the implementation of the subsidy policy [20]. Asking the family to complete the missing component would also have contributed to delaying care in a context where the obstetric kits were implemented [21].

Providers' knowledge of EOKs would also influence its implementation. Most of the staff (58.6\%) managing deliveries in the health facilities visited were NAs. Thus, there are real problems with the availability of human resources for obstetric care and those who are in the facilities are not regularly recycled [22]. In a context where there is a shortage of skilled personnel with work overload, it would be difficult to obtain an appreciable quality of maternal care [23]. This would be the case in our environment where the implementation of the EOKs might have led to an increase in the number of deliveries.

\section{Conclusion}

Staff implementing the EOKs was not sufficiently equipped with regards to their management. It is important to strengthen the capacities of all the actors on the policy of the kits and to set up a mechanism of financial motivation proportionate to the increase in the load in work. These measures would improve the access of the parturient to all the advantages related to the Kits.

\section{References}

1. OMS (2014) Mortalité maternelle. WHO.

2. World Health Organization, UNICEF (2015) Trends in maternal mortality: 1990-2015: estimates from WHO, UNICEF, UNFPA, World Bank Group and the United Nations Population Division.

3. World Health Organization, UNICEF (2014) Trends in maternal mortality: 1990 to 2013: estimates by WHO, UNICEF, UNFPA, The World Bank and the United Nations Population Division.

4. http://microdata.worldbank.org/index.php/catalog/1352

5. http://www.dhsprogram.com/publications/publication-fr163-dhs-final-reports.cfm

6. http://nada.stat.cm/index.php/catalog/34

7. De Brouwere V, Delvaux T, Leke R (2014) Achievements and lessons learnt from facility-based maternal death reviews in Cameroon. BJOG 121: 71-74.

8. http://www.statistics-cameroon.org/news.php?id=334
9. Tebeu PM, Ngassa P, Kouam L, Major AL, Fomulu JN (2007) Maternal mortality in Maroua Provincial Hospital, Cameroon (2003-2005). West Indian Med J 56: 502-507.

10. Richard F, Witter S, De Brouwere V (2000) Reducing financial barriers to obstetric care in low-income countries.

11. Richard F, Witter S, de Brouwere V (2010) Innovative Approaches to Reducing Financial Barriers to Obstetric Care in Low-Income Countries. Am J Public Health 100: 1845-1852.

12. Pearson L, Gandhi M, Admasu K, Keyes EB (2011) User fees and maternity services in Ethiopia. Int $\mathrm{J}$ Gynaecol Obstet 115: 310-315.

13. Borghi J, Ensor T, Somanathan A, Lissner C, Mills A (2006) Mobilising financial resources for maternal health. The Lancet 368: 1457-1465.

14. Perkins M, Brazier E, Themmen E, Bassane B, Diallo D, et al. (2009) Out-of-pocket costs for facility-based maternity care in three African countries. Health Policy Plan 24: 289-300.

15. Asante FA, Chikwama C, Daniels A, Armar-klemesu M (2007) Evaluating the economic outcomes of the policy of fee exemption for maternal delivery care in Ghana. Ghana Med J 41.

16. Witter S, Armar-Klemesu M, Dieng T (2008) National fee exemption schemes for deliveries: comparing the recent experiences of Ghana and Senegal. Stud Health Serv Organ Policy Ser 24: 167-198.

17. De Allegri M, Tiendrebéogo J, Müller O, Yé M, Jahn A, et al. (2015) Understanding home delivery in a context of user fee reduction: a cross-sectional mixed methods study in rural Burkina Faso. BMC Pregnancy Childbirth 15: 330.

18. Ben Ameur A, Ridde V, Bado AR, Ingabire M-G, Queuille $L$ (2012) User fee exemptions and excessive household spending for normal delivery in Burkina Faso: the need for careful implementation. BMC Health Serv Res 12: 412.

19. Tuffnell DJ, Wilkinson K, Beresford N (2001) Interval between decision and delivery by caesarean section-are current standards achievable? Observational case series. BMJ 322: 1330-1333.

20. Ridde V, Richard F, Bicaba A, Queuille L, Conombo G (2011) The national subsidy for deliveries and emergency obstetric care in Burkina Faso. Health Policy Plan 26: 30-40.

21. Gohou V, Ronsmans C, Kacou L, Yao K, Bohoussou KM, et al. (2004) Responsiveness to life-threatening obstetric emergencies in two hospitals in Abidjan, Côte d'Ivoire. Trop Med Int Health 9: 406-415.

22. Ashcroft B, Elstein M, Boreham N, Holm S (2003) Prospective semistructured observational study to identify risk attributable to staff deployment, training, and updating opportunities for midwives. BMJ 327: 584.

23. Gerein N, Green A, Pearson S (2006) The Implications of Shortages of Health Professionals for Maternal Health in Sub-Saharan Africa. Reprod Health Matters 14: 40-50. 